\title{
Journal of Nutritional Disorders \& Therapy
}

Gonzales et al., J Nutr Disorders Ther 2016, 6:4 DOI: 10.4172/2161-0509.1000202

\section{Consumption Pattern for Fruits and Vegetables of Some Filipino Adolescents in Selected Public Schools in the City of Manila}

\author{
Josefina Taguinod Gonzales ${ }^{1^{*}}$, Joop Van Raaij ${ }^{2}$ and Zenaida Villamin Narciso ${ }^{3}$ \\ ${ }^{1}$ Food and Nutrition Research Institute, Sta. Rosa City, Laguna, Philippines \\ ${ }^{2}$ Wageningen University \& Research Center, The Netherlands \\ ${ }^{3}$ Food Nutrition Research Institute, Dost Compound General Santos ave, Taguig, Metro Manila, Philippines
}

"Corresponding author: Josefina Taguinod Gonzales, Food and Nutrition Research Institute, Sta. Rosa City, Laguna, Philippines, Tel: 09274802493; E-mail: jogon8@yahoo.com

Received date: October 30, 2016; Accepted date: December 28, 2016; Published date: December 31, 2016

Copyright: @ 2016 Gonzales JT, et al. This is an open-access article distributed under the terms of the Creative Commons Attribution License, which permits unrestricted use, distribution, and reproduction in any medium, provided the original author and source are credited.

\begin{abstract}
The study aimed to: (a) determine perceptions regarding fruits and vegetables (b) identify selected practices on fruit and vegetables consumption (c) assess consumption of fruit and vegetables in terms of serving and grams per day and (d) identify factors affecting fruit and vegetable consumption. The study was conducted in seven randomly selected public schools and three public colleges in the City of Manila. Two hundred randomly selected students aged 12-16 years and 17-20 years were personally interviewed using a structured questionnaire. A food frequency questionnaire was used to determine the past month's fruit and vegetable consumption. Data were analysed using the Statistical Package for the Social Sciences (SPSS). Descriptive statistics, like frequencies, means and percentages, ANOVA, T-test and simple correlation were used. Results showed that inadequate consumption of vegetables was prevalent among the study populations but fruit intake was higher than the Philippine recommendation. Fruit and vegetable intakes varied with age and sex. Male adolescents consumed more vegetables compared to their female counterparts. Female adolescents consumed more fruits than their male counterparts. Generally, the adolescents had a good perception of fruits and vegetables. The study concluded that Filipino adolescents are consuming substantially fewer servings of vegetables than the recommended daily allowances but fruit intake was higher than the recommended. The study advanced recommendations useful for promoting fruit and vegetable consumption among adolescents and for future studies focused on nutritional behaviour change related to fruit and vegetable consumption among adolescent.
\end{abstract}

Keywords: Fruit and vegetable consumption; Diseases; Food intake

\section{Introduction}

Inadequate fruit and vegetable consumption has been linked to certain types of cancer and other diseases. Several studies have demonstrated significant protective effects of intake of fruits and vegetables against cancer. It has been estimated that at least $35 \%$ of cancer deaths may be attributable to unhealthy diets [1]. Of all the dietary factors postulated to cause cancer, the epidemiological evidence is strongest for an association with low fruit and vegetable consumption.

It has been suggested that five servings of fruit and vegetables per day would confer considerable benefits to health. Due to the many health benefits associated with fruits and vegetables, the national recommendation is increased consumption. However, numerous surveys have reported that consumption patterns are considerably lower than the recommended amount.

Results of the food consumption surveys in the Philippines conducted by the Food and Nutrition Research Institute-Department of Science and Technology (FNRI-DOST) showed that the average consumption of green, leafy, and yellow vegetables and vitamin C-rich fruits is low in the Filipino diet. Although fruits are plentiful in the Philippines, the surveys seem to show that fruits are not a significant part of the daily diet of Filipinos since they are considered only optional items. Fruits are often eaten as dessert [2]. Likewise, results from the second National Health and Nutrition Examination Survey (NHANES II) in the United States (US) showed that $17 \%$ of the population did not eat any vegetables at all on the day of the survey, and $41 \%$ had no fruit or fruit juice. Only $9 \%$ consumed five servings of fruits and vegetables a day [1].

Studies on children and adolescents have similarly reported large gaps between recommended amounts and actual consumption patterns. National surveys in the US indicate that adolescents consume an inherently poor diet. They often skip breakfast and/or lunch and have meals low in nutrients. Fewer than $25 \%$ of adolescents reported the consumption of nutritious snacks such as fruits, vegetables, juice and low-fat milk [3]. Several surveys have reported that inadequate fruit and vegetable consumption is prevalent among children and adolescents. These potentially adverse dietary practices are particularly important during the period of adolescence. It is during this developmental phase that negative dietary practices can become the foundation of lifestyles in later years.

There is strong and consistent evidence that eating fruits and vegetables reduces the risks of major chronic diseases like cardiovascular disease and cancer [4]. Worldwide recommendations for increasing intake of fruits and vegetables have been issued. Despite these recommendations, in general, most people may not eat enough fruits and vegetables. Adolescents in industrialized countries typically eat more high-fat and high-sugar foods and less fruits, vegetables and dairy products than they need. 
In view of past studies that have documented the high prevalence of unhealthy eating behavior including the low consumption of fruits and vegetables, this study looked into the quality of adolescents' diets particularly fruit and vegetable intake. Adequate nutrition in this stage of life is of key importance to meet the requirements for normal growth and development [5].

This study in general, aimed to determine perceptions, practices and consumption of fruits and vegetables among adolescents in public schools of the City of Manila. Specifically, it sought to: (a) determine perceptions of these adolescents regarding fruits and vegetables (b) identify selected practices on fruit and vegetable consumption (c) assess consumption of fruits and vegetables in terms of serving and grams per day (d) identify factors associated with socio-demographic characteristics affecting fruit and vegetable consumption.

\section{Materials and Methods}

The study was conducted in selected public schools in the City of Manila. These schools were chosen as study sites because students here are from depressed urban communities and low-income families.

\section{Sampling design}

The study employed the two-stage sampling design where random selection was done at the public school and student levels. The number of public schools was predetermined by power calculation while the number of students per school was determined using proportional allocation based on the complete list of enrolled students secured from each school. From the list of 29 public secondary schools and three public colleges in the city, seven secondary schools and the three colleges were taken. Two hundred 12-16 and 17-20 years old students were selected using systematic random sampling.

\section{Data collection procedure}

The data collection was done through personal interview using a structured questionnaire. The questionnaire consisted of three parts: socio-demographic characteristics, food frequency and qualitative information. The socio-demographic characteristics included age, sex, parents' educational level and occupation.

The Food Frequency Questionnaire (FFQ) was patterned from the Food Consumption Surveys of FNRI-DOST. This included questions on commonly eaten fruits and vegetables, green leafy and yellow vegetables and vitamin C-rich fruits and their amounts and frequencies of intake for the past month. Corresponding weights in grams of the foods were applied. Standard weights and measures from the Food Consumption Surveys Division of the FNRI and the Food Exchange List (FEL) were used as reference for estimating serving portion/sizes. The qualitative portion of the questionnaire was used to determine factors that may affect the fruit and vegetables consumption among adolescents. Questions on knowledge, attitude and practice, and possible barriers to fruit and vegetable consumption were asked. Positive perception towards fruits and vegetables was determined in the open-ended questions. Answers were grouped and tabulated.

\section{Data processing and analysis}

Accomplished questionnaires were checked and edited for inconsistencies. Variables were pre-coded prior to data entry. Printouts from the raw data were edited and cleaned to facilitate a smooth flow of analysis. Data were analyzed using the Statistical Package for the Social Sciences (SPSS). Descriptive statistics, like frequencies, means and percentages, ANOVA, T-test and simple correlation were used.

\section{Results}

As shown in Table 1, the respondents were equally divided so that there were 100 males and 100 females. There were slightly more students belonging to the older group of 17-20 years of age. The highest proportion was those in 1st year high school and 3rd year college (16\%).

\begin{tabular}{|l|l|l|}
\hline Characteristics of subjects & N (200) & $\%$ \\
\hline Sex & 100 & 50 \\
\hline Male & 100 & 50 \\
\hline Female & \multicolumn{2}{|l|}{} \\
\hline Age group & 92 & 46 \\
\hline 12-16 & 108 & 54 \\
\hline 17-20 & \multicolumn{2}{|l|}{} \\
\hline Educational level & 32 & 16 \\
\hline 1st year high school & 21 & 10.5 \\
\hline 2nd year high school & 23 & 11.5 \\
\hline 3rd year high school & 17 & 8.5 \\
\hline 4th year high school & 29 & 14.5 \\
\hline 1st year college & 27 & 13.5 \\
\hline 2nd year college & 32 & 16 \\
\hline 3rd year college & 19 & 9.5 \\
\hline 4th year college & \multicolumn{2}{|l|}{} \\
\hline
\end{tabular}

Table 1: Profile of respondents.

\section{Perception on fruits and vegetables}

Table 2 presents the adolescents' perceptions on fruits and vegetables. Most of the adolescents perceived fruit and vegetables to have a positive effect on their bodies. Perceptions were lumped and summed up to the top three answers, (a) they make one healthy and strong (b) they increase resistance to infection and (c) are more nutritious. More female than male adolescents perceived fruits and vegetables to make them healthy and strong. More male particularly younger ones, than females perceived fruits and vegetables to increase resistance against infection. More males than females perceived fruits and vegetables as more nutritious because they contains more vitamins and minerals.

\section{Selected practices on fruit and vegetable consumption}

Almost half of the subjects did not at all eat fruits in school during snack time. However, more than $40 \%$ of the adolescent's ate fruits in school and at home sometimes. Only $6.5 \%$ claimed they ate fruit as snack in school most of the time while $42.2 \%$ said they ate fruits as snack at home. 
Citation: Gonzales JT, Raaij JV, Narciso ZV (2016) Consumption Pattern for Fruits and Vegetables of Some Filipino Adolescents in Selected

Page 3 of 7

\begin{tabular}{|c|c|c|c|}
\hline Perception & Sex and Age Group & $\mathbf{N}$ & $\%$ \\
\hline \multirow{7}{*}{$\begin{array}{l}\text { 1. Healthy and strong/for } \\
\text { growth and development }\end{array}$} & \multicolumn{3}{|l|}{ Male } \\
\hline & $12-16$ years & 31 & 22.1 \\
\hline & $17-20$ years & 28 & 20 \\
\hline & Female & & \\
\hline & $12-16$ years & 38 & 27.1 \\
\hline & $17-20$ years & 43 & 30.7 \\
\hline & Total & 140 & 99.9 \\
\hline \multirow{7}{*}{$\begin{array}{l}\text { 2. Increase resistance against } \\
\text { infection/prevents from getting } \\
\text { sick/improve immune system }\end{array}$} & \multicolumn{3}{|l|}{ Male } \\
\hline & $12-16$ years & 17 & 40.5 \\
\hline & $17-20$ years & 12 & 28.6 \\
\hline & \multicolumn{2}{|l|}{ Female } & \\
\hline & $12-16$ years & 5 & 11.9 \\
\hline & $17-20$ years & 8 & 19 \\
\hline & Total & 42 & 100 \\
\hline \multirow{7}{*}{$\begin{array}{l}\text { 3. More nutritious/more } \\
\text { vitamins and minerals }\end{array}$} & \multicolumn{3}{|l|}{ Male } \\
\hline & $12-16$ years & 9 & 23.7 \\
\hline & $17-20$ years & 13 & 34.2 \\
\hline & \multicolumn{2}{|l|}{ Female } & \\
\hline & $12-16$ years & 4 & 10.5 \\
\hline & $17-20$ years & 12 & 31.6 \\
\hline & Total & 38 & 100 \\
\hline
\end{tabular}

Table 2: Perception on fruits and vegetables among selected filipino adolescents.

About a quarter said they did not at all eat vegetables in school and only $2 \%$ said they did not at all eat vegetable at home.

\begin{tabular}{|l|l|l|l|}
\hline Selected Practices & $\begin{array}{l}\text { Yes, most of the } \\
\text { time }\end{array}$ & $\begin{array}{l}\text { Yes, } \\
\text { sometimes }\end{array}$ & $\begin{array}{l}\text { No, not at } \\
\text { all }\end{array}$ \\
\hline & \multicolumn{1}{|c|}{$\%$} & \multicolumn{1}{|c|}{$\%$} \\
\hline $\begin{array}{l}\text { Fruit as snack in } \\
\text { school }\end{array}$ & 6.5 & 44.2 & 49.2 \\
\hline Fruit as snack at home & 41.2 & 47.7 & 11 \\
\hline $\begin{array}{l}\text { Ate vegetable in } \\
\text { school }\end{array}$ & 17.5 & 56 & 26.5 \\
\hline Ate vegetableat home & 46 & 52 & 2 \\
\hline
\end{tabular}

Table 3: Selected practices on fruit and vegetables consumption among Filipino adolescents.

More than half of the subjects, said that they sometimes ate vegetables in school (56\%) and at home (52\%) during meals. While $46 \%$ ate vegetables at home most of the time. Less than a fifth $(17.5 \%)$ ate vegetables in school most of the time. Nearly half (46\%) ate vegetables at home most of the time (Table 3).

\section{Consumption pattern of fruits and vegetables}

As shown in Table 4, the mean number of servings of fruit per day among the male adolescents was 4.1 and 4.3 among the female adolescents. Younger adolescents (12-16 years), specifically the females consumed more servings of fruits compared to older adolescents (17-20 years) but the difference was not significant. The mean number of servings per day of vegetable was 1.9 and 1.0 for males and females respectively, which were found to be significantly different.

\begin{tabular}{|c|c|c|c|c|}
\hline \multirow[t]{2}{*}{ Sex and Age group } & \multicolumn{2}{|c|}{ Fruit } & \multicolumn{2}{|c|}{ Vegetable } \\
\hline & $\mathbf{N}$ & Mean \pm SD & $\mathbf{N}$ & Mean \pm SD \\
\hline \multicolumn{5}{|l|}{ Male } \\
\hline $12-16$ years & 50 & $4.5 \pm 3.6$ & 49 & $1.8 \pm 2.2^{\mathrm{a}}$ \\
\hline $17-20$ years & 50 & $3.7 \pm 2.8$ & 50 & $2.0 \pm 23^{a}$ \\
\hline Total & 100 & $4.1 \pm 3.2$ & 99 & $1.9 \pm 2.2^{\mathrm{a}}$ \\
\hline \multicolumn{5}{|l|}{ Female } \\
\hline $12-16$ years & 42 & $5.1 \pm 3.9^{b}$ & 42 & $1.0 \pm 1.7$ \\
\hline $17-20$ years & 57 & $3.8 \pm 3.1$ & 58 & $1.1 \pm 1.2$ \\
\hline Total & 99 & $4.3 \pm 3.5$ & 100 & $1.0 \pm 1.0$ \\
\hline \multicolumn{5}{|c|}{ aSignificantly different between sexes, T-Test, $p<0.05$. } \\
\hline
\end{tabular}

Table 4: Number of servings per day of fruits and vegetables among selected filipino adolescents.

As shown in Table 5, mean fruit intakes in grams per day among the female subjects were significantly higher in the 12-16 years age group than in the 17-20 years group for both sexes.

\begin{tabular}{|c|c|c|c|c|}
\hline \multirow[t]{2}{*}{ Sex and Age group } & \multicolumn{2}{|c|}{ Fruit } & \multicolumn{2}{|c|}{ Vegetable } \\
\hline & $\mathbf{N}$ & Mean \pm SD & $\mathbf{N}$ & Mean \pm SD \\
\hline \multicolumn{5}{|l|}{ Male } \\
\hline $12-16$ years & 50 & $284 \pm 225$ & 49 & $95 \pm 112^{b}$ \\
\hline $17-20$ years & 50 & $229 \pm 177$ & 50 & $119 \pm 173^{b}$ \\
\hline Total & 100 & $257 \pm 203$ & 99 & $107 \pm 146^{b}$ \\
\hline \multicolumn{5}{|l|}{ Female } \\
\hline $12-16$ years & 42 & $319 \pm 245^{a}$ & 42 & $52 \pm 40$ \\
\hline $17-20$ years & 57 & $232 \pm 196$ & 58 & $59 \pm 68$ \\
\hline Total & 99 & $267 \pm 221$ & 100 & $56 \pm 58$ \\
\hline \multicolumn{5}{|c|}{ aSignificantly different between age group, T-test, $p<0.05$. } \\
\hline
\end{tabular}

Table 5: Fruit and vegetable intake among selected filipino adolescents. 
Page 4 of 7

Among the males, there was also higher mean fruit intake among the younger group, but the difference was not significant. The mean vegetable intakes were significantly higher in males, specifically the 17-20 years of age, than in females.
Table 6 shows that Statistical test using ANOVA showed no significant difference in fruit and vegetable intake with parents' educational and occupational level.

\begin{tabular}{|c|c|c|c|c|c|c|}
\hline \multirow{2}{*}{ Educational Level } & \multicolumn{3}{|c|}{ Father } & \multicolumn{3}{|c|}{ Mother } \\
\hline & $\mathbf{N}$ & Fruit (g) & Vegetable $(\mathrm{g})$ & $\mathbf{N}$ & Fruit (g) & Vegetable (g) \\
\hline & & Mean \pm SD & Mean \pm SD & & Mean \pm SD & Mean \pm SD \\
\hline 1. Elementary level/graduate & 15 & $247 \pm 223$ & $86 \pm 83$ & 15 & $317 \pm 240$ & $86 \pm 81$ \\
\hline 2. High school level/graduate & 76 & $257 \pm 199$ & $84 \pm 146$ & 76 & $317 \pm 240$ & $73 \pm 68$ \\
\hline 3. College level/graduate & 97 & $272 \pm 220$ & $80 \pm 93$ & 102 & $317 \pm 240$ & $87 \pm 143$ \\
\hline Not specified/deceased & 12 & $239 \pm 234$ & $62 \pm 52$ & 7 & $317 \pm 240$ & $63 \pm 60$ \\
\hline 1. Housekeeper/jobless & 8 & $178 \pm 169$ & $48 \pm 25$ & 107 & $277 \pm 231$ & $82 \pm 126$ \\
\hline 2. Clerk, employees, laborer & 136 & $275 \pm 225$ & $76 \pm 115$ & 62 & $255 \pm 200$ & $84 \pm 98$ \\
\hline 3. Self-employed & 8 & $153 \pm 65$ & $85 \pm 75$ & 10 & $273 \pm 177$ & $136 \pm 137$ \\
\hline 4. Professionals & 22 & $258 \pm 157$ & $70 \pm 61$ & 15 & $212 \pm 150$ & $45 \pm 41$ \\
\hline Not specified/deceased & 26 & $261 \pm 223$ & $125 \pm 150$ & 6 & $208 \pm 198$ & $24 \pm 28$ \\
\hline
\end{tabular}

Table 6: Fruit and vegetable intake by parent's educational and occupational.

Reasons for not choosing fruits and vegetables in school and at home were elicited using the qualitative questionnaire as shown in Table 7. Possible barriers to fruit and vegetable consumption in school and at home were identified. Data show that the unavailability of fruits in school and at home was the number one reason for low fruit consumption. On the other hand, price and palatability were the main reasons for low vegetable consumption.

\section{Discussion}

\section{Characteristics of the study population}

The study site which includes public high schools and college schools may not have provided a representative picture of adolescents in the city of Manila. However, this city was chosen for its proximity and for the administrative feasibility of its smaller size compared to Metro Manila, which had 13 municipalities and cities at the time of the study.

The study population belonged to low-income families from depressed urban communities. More than $90 \%$ of the adolescents' parents reached college, some were college graduates and some had post graduate degrees. However, the level of education did not reflect their kind of occupation. More than $90 \%$ of the parents were employed either as laborer, carpenter, vendor or saleslady. Almost $50 \%$ of the mothers were plain housekeepers.

\section{Limitations of the methodology used}

Perceptions and selected practices of adolescents regarding daily fruit and vegetable consumption were explored in the qualitative portion of the questionnaire. Perceptions were lumped and summed up only to top three answers. Focus group discussion was not carried out so that in-depth answers to the qualitative portion of the questionnaire were not elicited in the study.

Fruit and vegetable consumption was assessed using the Food Frequency Questionnaire (FFQ). A shortened version of the FFQ adopted from the questionnaire of the Nutritional Assessment and Monitoring Division of FNRI-DOST was used. It consisted of 32 commonly eaten fruits and vegetables particularly green leafy and yellow vegetables and vitamin C-rich fruits. Standard serving size definitions according to the standard weights and measures and the Food Exchange Lists from the FNRI-DOST were also used.

Several studies have used the same questionnaire and methodology, such as the study of Sztainer et al. [1] which was also conducted among adolescents. Dennison et al. [6] also used a similar method in calculating fruit and vegetable consumption among young children. In that study, fruit drinks and or juice blends that were not $100 \%$ fruit juice were not included in calculating fruit servings. In the present study, "fruit juices" were also not included in calculating fruit servings because fruit drinks mentioned by the respondents were in powdered form, and the juice blends were not 100\% fruit juice.

Moreover, the data generated from this study may likewise, not be representative of the adolescents' fruit and vegetables intake. Since the technique relied heavily on memory and recall, over- or underestimation of the fruit and vegetable intake is possible. It has been frequently said that there is no perfect measure of dietary intake. Measurements have errors. Although these errors differ in their magnitude, among the available and feasible comparison methods for validating a food frequency questionnaire, diet records are likely to have the least correlated errors. Major sources of errors associated with FFQ are due to the restrictions imposed by a fixed list of foods, memory, perception of portion sizes, and interpretation of questions. Diet records minimally share these sources of error because diet records are open-ended; they do not depend on memory [7]. A study 
Page 5 of 7

conducted in Finland by Willet and co-workers [7] provided the opportunity to compare the relative validities of an extremely short questionnaire and an extremely detailed questionnaire, which were both self-administered. When compared with the mean of two-day diet records, reasonable correlation was seen with both methods. Thus, the food frequency approach appears to be robust across a wide range of applications [7].

\begin{tabular}{|l|l|l|}
\hline Possible barriers to fruit and vegetables consumption & N & $\%$ \\
\hline Barriers to fruit consumption in school & 55 & 27.5 \\
\hline Not available in school canteen & 20 & 10 \\
\hline Expensive & 41 & 20.5 \\
\hline Prefer other snack food & 84 & 42 \\
\hline No barrier & &
\end{tabular}

Barrier to fruit consumption at home

\begin{tabular}{|l|l|l|}
\hline Not available & 16 & 8 \\
\hline Expensive & 3 & 1.5 \\
\hline Prefer other food & 8 & 4 \\
\hline No barrier & 173 & 86.5 \\
\hline
\end{tabular}

Barriers to vegetable consumption in school

\begin{tabular}{|l|l|l|}
\hline Expensive & 9 & 4.5 \\
\hline Palatability-don't like the taste & 26 & 13 \\
\hline Not available in school canteen & 7 & 3.5 \\
\hline Other reasons (mushy, spoil easily) & 24 & 12 \\
\hline No barrier & 134 & 67 \\
\hline
\end{tabular}

Barrier to vegetable consumption at home

\begin{tabular}{|l|l|l|}
\hline Don't like the taste & 1 & 0.5 \\
\hline Time consuming to prepare & 2 & 1 \\
\hline No barrier & 197 & 98.5 \\
\hline
\end{tabular}

Table 7: Barriers to fruit and vegetables consumption among filipino adolescents.

\section{Perceptions regarding fruits and vegetables}

Generally, the adolescents in this study have a good perception of fruits and vegetables. Fruits were perceived as having a positive effect on their bodies; vegetables were viewed as being important to good health. However, there were greater barriers to consumption of these foods. Among the barriers to fruit consumption in the school which were identified in the study was the availability of fruits in school canteens or cafeteria. Most of the respondents said that fruits were not available in their school canteens, while some of them preferred other foods as snack food instead of fruits. Others found fruits too expensive compared to other food stuff. The same reasons were cited for not choosing fruit as a snack food at home. Most of them answered that fruits were not available at home and that they preferred other foods.
On the other hand, vegetables were seldom eaten in school during mealtime because the respondents did not like the taste. Others found these too mushy and easily spoiled. At home, they seldom ate vegetables because most of them found preparing vegetables timeconsuming and they disliked the taste. Preparation time was also a barrier to increased vegetable consumption. This was due to irregular working hours and the busy lifestyle of the adolescents and the mothers. Adolescents preferred to eat other foods like, chips, high-fat and high-sugar foodstuffs instead of fruits as snacks. Vegetables were mushy, looked and tasted bad, were not convenient to prepare or fix before going to school and took a lot of time to prepare. These findings were consistent with other studies such as the study of Reicks et al. [8] and Pollard et al. [9]. Other constraints which can be barriers to fruit and vegetable consumption as identified by the reasons mentioned in Reicks [8] were the following: (a) Don't know how to fix vegetables in ways that tasted good; (b) not sure of safety of chemicals used in vegetable production; (c) had to give up other foods to buy fruits and vegetables; (d) had to limit storage space for fresh fruits and vegetables; and (e) childhood memories of being forced to eat vegetables.

\section{Selected practices on fruit and vegetables consumption}

Findings revealed that most of the adolescents did not eat fruit as a snack food in school and at home. Similar studies, like the study of Beech et al. [3] indicated that adolescents consume an inherently poor diet. The most frequently reported snacks among adolescents were candy, soda and pastries. Only less than a quarter of the adolescents reported consumption of nutritious snacks such as fruits, vegetables, juice and low fat milk [3]. These findings can be attributed to the possible barriers to fruit and vegetable consumption and sociodemographic characteristics of the subjects.

\section{Fruit and vegetable consumption in terms of servings per day}

The results indicated that majority of the adolescents met the recommended servings of at least 2 servings of fruit per day, based on the Nutritional Guidelines for Filipinos (NGF) and the Food Guide Pyramid developed by the US Department of Agriculture (USDA). The Pyramid recommends 2 to 4 servings/day of fruits and 3 to 5 servings/day of vegetables [6]. This quantification of serving sizes and number is consistent with the recommendation to eat 5 servings of fruits and vegetables combined, as promoted by the National Cancer Institute's Five A Day for Better Health Campaign [10]. Results showed that the mean intake of fruits among the adolescents in this study was 4.2-servings/per day, The number of servings of fruits eaten was more than the recommended. On the other hand, vegetable consumption was below the recommendation. The mean number of serving of vegetables was only 1.5 serving/day. Thus, vegetable intake fell below the recommendation. The study of Beech et al. [3] about knowledge, attitudes and practices related to fruit and vegetable consumption among high school students showed that the Bogalusa Heart Study data indicated that 16-year-old high school students consumed an average 1.0 servings of fruit per day and 1.6 servings of vegetable per day. Recent national surveys in the United States confirmed that fruit and vegetable intake among adolescents, was consistently below the recommended five or more daily servings of fruits and vegetables [3]. Data from similar studies conducted in the Philippines and other Asian countries are limited to provide comparisons. 


\section{Fruit and vegetable consumption in terms of grams per day}

The Recommended Dietary Allowance (RDA) for Filipinos for specific food groups recommends 200 grams of fruit per day and 170 grams of vegetable per day. Results of the study revealed that the average fruit intake of the adolescents was 262 grams per day, which is again higher than the recommendation. Mean intake of vegetables among the subject was only 81 grams per day. Intake was below the recommendation of 170 grams per day. WHO recommends 400 grams of fruits and vegetables per day.

\section{Fruit and vegetable intake between sex and age group}

This study sought to identify the variations of fruit and vegetables intake of adolescents due to age and sex. Findings of the study indicated that fruit and vegetable consumption varies with age and sex. Younger female adolescents (12-16 years) consumed more fruits compared to older adolescents and male counterparts. While older male adolescents (17-20 years) consumed more vegetables compared to younger adolescents and female counterparts. Female adolescents were more conscious of the health benefits of eating fruits, fruits were perceived to make them slim, to have a beautiful hair, skin and body. However, male adolescents consumed more vegetables because it was perceived to make them strong and healthy. Gender differences were slight with higher percentage of males reporting inadequate fruit intake and females with inadequate vegetable intake. Age differences in consumption patterns were slightly significant. Sztainer et al. [1] reported similar findings among adolescents in public secondary school in Minnesota. Reynolds et al. [11-15] mentioned that among the children aged 2-18 years, fruit and vegetables consumption was 3.5 servings per day with consumption increasing in older males. A similar study conducted in the United Kingdom among low-income children aged 10-15 years found out that girls consumed more servings of fruit than boys. Gender differences were more pronounced in the older children [11,16-19]. Statistical test using ANOVA showed significant difference in vegetable intake between sex of the same age groups and significant differences in fruit intake between age group of the same sex.

\section{Conclusions}

- Generally, the adolescents had a good perception of fruits and vegetables. Fruits were perceived as having a positive effect on their bodies; vegetables were viewed as being good for the health.

- Almost half of the adolescents did not at all eat fruits in school during snack time. More than half of the adolescents said that they sometimes ate vegetables in school and at home during meals.

- Filipino adolescents were consuming substantially fewer servings of vegetables than the recommendation but fruit intake was higher than the recommended amount.

- Several factors like age and sex, availability, food preference and time were associated with fruit and vegetable consumption

\section{Recommendations for increasing vegetable consumption}

- For adolescents to increase the liking for vegetables, provide simple and convenient tasty recipe and involve them in the fruit and vegetable preparation.
- $\quad$ Encourage parents and school canteen staff to not only offer a variety of fruits and vegetables, but also model eating them and patronizing food establishments that serve fruits and vegetables.

- Consider gender and age differences in fruit and vegetable intake for nutrition program targeting.

\section{Recommendations for future studies}

Future studies focusing on nutritional behavior, adolescent's food preferences, eating patterns, knowledge and attitudes regarding fruit and vegetables on diverse adolescent populations using improved methodologies. Need expansion of these studies to private schools in Manila for comparison of results.

\section{References}

1. Sztainer-Neumark D, Story M, Resnick MD, Blum RW (1996) Correlates of Inadequate Fruit and Vegetable Consumption among Adolescents. Prev Med 25: 497-505.

2. Nutritional Guidelines for Filipinos Revised Edition 2000.

3. Beech BM, Rice R, Myers L, Johnson C, Nicklas TA (1999) Knowledge, Attitudes, and Practices Related to Fruit and Vegetable Consumption of High School Students. J Adolesc Health 24: 244-250.

4. Trudeau E, Kristal AR, Li S, Patterson RE (1998) Demographic and psychosocial predictors of fruit and vegetable intakes differ: Implications for Dietary interventions. J Am Diet Assoc 98: 1412-1417.

5. Gabhainn SN, Nolan G, Kelleher C, Friel S (2002) Dieting patterns and related lifestyles of school-aged children in the Republic of Ireland. Public Health Nutr 5: 457-462.

6. Dennison BA, Rockwell HL, Baker SL (1998) Fruit and Vegetable Intake in Young Children. J Am College of Nutrition 17: 371-378.

7. Willet W, Lenart E (1998) Reproducibility and Validity of Food Frequency Questionnaire. Nutritional Epidemiology (2nd edn), Oxford press.

8. Reicks M, Randall JL, Haynes BJ (1994) Factors affecting consumption of fruits and vegetables by low-income families. J Am Diet Assoc 94: 1309-1311.

9. Pollard J, Greenwood D, Kirk S, Cade J (2002) Motivations for fruit and vegetable consumption in the UK Women's Cohort Study. J Public Health Nutr 5: 479-486.

10. Krebs-Smith SM, Kantor LS (2001) Choose a Variety of Fruits and Vegetables Daily: Understanding the Complexities. J Nutr 131: 487S-501S.

11. Reynolds KD (1999) Patterns in Child and adolescent Consumption of Fruit and Vegetables: Effects of Gender and Ethnicity across Four Sites. J Am Coll Nutr 18: 248-254.

12. Aboud FE (2002) Cultural perspectives on the interactions between nutrition, health and psychological functioning. Online Readings in Psychology and Culture.

13. Andersen LF, Johansson L, Solvoll K (2002) Usefulness of a short food frequency questionnaire for screening of low intake of fruit and vegetable and for intake of fat. Eur J Public Health 12: 208-213.

14. Cotugna N, Fleming E (1998) Comparison of standard and portionassisted responses to a brief fruit and vegetable food frequency questionnaire in a Hispanic WIC population. J Am Diet Assoc 98: $1462-1464$.

15. Cullen KW, Bartholomew LK, Parcel GS, Koehly L (1998) Measuring Stage of Change for Fruit and Vegetable Consumption in 9-to 12 year-old Girls. J Behav Med 21: 241-254.

16. Getty V, Evers B (2003) Increasing Fruit and Vegetable Consumption by Children and Adolescents. Electronic Food Rap 7.

17. Gibson EL, Wardle J, Watts CJ (1998) Fruit and Vegetable Consumption, Nutritional Knowledge and Beliefs in Mothers and Children. Apetite 31: 205-228. 
Citation: Gonzales JT, Raaij JV, Narciso ZV (2016) Consumption Pattern for Fruits and Vegetables of Some Filipino Adolescents in Selected Public Schools in the City of Manila. J Nutr Disorders Ther 6: 202. doi:10.4172/2161-0509.1000202

Page 7 of 7

18. Hampl JS, Taylor CA, Johnston CS (1999) Intakes of Vitamin C, Vegetables and Fruits: which schoolchildren are at Risk? J Am Coll Nutr 18: $582-590$
19. Treiman K, Freimuth V, Damron D (1996) Attitudes and Behaviors Related to Fruits and Vegetables among Low-income women in the WIC Program. J Nutrition Edu 28: 149-156. 